\section{SUBSÍDIOS PARA CRITÉRIOS DE PRESERVAÇÃO ATIVA DE MONSARAZ'}

Américo Pellegrini Filho

RESUMO: Localizada a cerca de 3 quilômetros da fronteira fluvial com a Espanha, a vila medieval de Monsaraz acha-se implantada no alto de um morro isolado na planicie que domina a paisagem natural do leste-sul de Portugal - a região do Alentejo fronteiriço. Desprovida de importância econômica, a vila atravessou séculos estagnada, o que the possibilitou manter seu antigo casario intra-muros; também não se desenvolveu extra-muralha, o que lhe permite dispor de entorno verde cultivado. Um caso raro de conjunto com enorme valor para turismo eco-cultural.

PALAVRAS-CHAVE: Turismo cultural; patrimônio cultural e natural; preservação ativa; critérios; Monsaraz; Portugal.

ABSTRACT: About 3 kilometers distant from the fluvial boundary with Spain, the medieval village of Monsaraz was built at the top of an isolated hill in the natural landscape dominant plains in south-eastern Portugal - the frontier Alentejo region. With no economic importance, the village went through centuries of stagnation, fact that made possible the maintenance of its olu housing within the walls. The village did not develop outside its walls either.thus keeping cultivated green surroundings. A very unusual ensemble with extraordinary' value for eco-cultural tourism.

KEY WORDS: Cultural tourism; cultural and natural heritage; active preservation; criteria; Monsaraz; Portugal.

\section{CONSIDERAÇÕES INICIAIS}

Superadas as inúmeras vicissitudes dos tempos de guerras contra 0 domínio dos árabes e contra o poder de Castela, portanto cumprida sua

1. Trabalho realizado durante viagem de estudos a Portugal.

2. Professor Livre Docente do Curso de Turismo da ECAVUSP.

End. para corresp.: ECA-USP - Departamento de Relaçōes Públicas, Propaganda e TurismoCidade Universitária "Armando de Salles Oliveira"- Av. Prof. Lúcio M. Rodrigues, 443. Bloco B - 05508-900 - Sào Paulo - SP - Brasil - Fax (011) 81 8-4331. função militar na fronteira do Alentejo, a vila medieval do Mosaraz manteve-se de uma forma rara em Portugal e na Península Ibérica, conservando-se quase inteiramente como um conjunto magnífico de patrimônio arquitetônico e urbanístico antigo. Desnecessário lembrar aqui.o que já foi estudado por Túlio Espanca, José Pires Gonçalves, José Cultileiro e Manuel Inácio Pestana, além de teses de Francisco Ramos e João Rosado Correia, a realçar o indiscutivel valor histórico, artístico e social de Monsaraz.

Atravessando centúrias e sobrepondo-se a naturais mudanças socioculturais, Monsaraz chega ao século XX na condição de exemplar raro como patrimônio cultural: 105 fogos $^{3}$ habitados, 3 igrejas católicas e 1 ex-igreja (dessacralizada) adaptada para eventos culturais, o Castelo, a Torre do Relógio na entrada principal, 15 construções em ruinas ou lotes desocupados (juntamente com o Arrabalde) ${ }^{4}$. Mas é importante lembrar também a paisagem envolvente, num raio de cerca de 8 quilômetros, uma vez que patrimônio natural e patrimônio cultural são conceitos interligados. De modo que. em poucas palavras, é forçoso reconhecer-se que a Monsaraz de hoje apresenta-se com inegável vocação para o turismo ecocultural. Essa situação diferencial da vila, graças a não ter experimentado crescimentosignificativo nos séculos XIX e XX (o que aconteceu e acontece em outros núcleos fortificados e com valor histórico-artístico de diversos países), lhe dá méritos para poder ser considerada Patrimônio da Humanidade pela UNESCO, como se aguarda.

\section{CRITÉRIOS PARA PRESERVAÇÃO ATIVA}

Um tal diagnóstico não constitui propriamente novidade. Todavia, considerando a rapidez com que ocorrem mudanças da sociedade industrial contemporânea, é urgente que se estabeleçam critérios com o objetivo de permitir a preservação ativa ${ }^{5}$ desse conjunto significativo ${ }^{6}$, e seu aproveitamento racional em atividades de turismo que tenham por centro de aten-

3. Fogos: residências, moradias (conforme uso corrente em Portugal)

4. Dados referentes a 1991, de Monsaraz e Arrabalde (Instituto Nacional de Estatisticas e Junta de Freguesia de Monsaraz)

5. Conceituação de preservação ativa: “... conservação de bens naturais e culturais, dando-se-lhes ao mesmo tempo uma função conveniente, com soluções adequadas ao desejado progresso; portanto, implicando o uso adequado de atrativos da natureza e da cultura , porém evitando-se ou minimizando-se prejuizo a eles ou sua perda. Uma questão de desenvolvimento sustentado ..." (Pellegrini Filho, 1993).

6. A preservação de conjuntos representativos deve ter total prioridade em relação a monumentos isolados, conforme a Unesco (1972). 
ções a herança cultural, tanto no plano material quanto no espiritual. ao mesmo tempo cm que se garanta a melhor qualidade de vida para seus habitantes. ${ }^{7}$

Procurando registrar, aqui, alguns subsidios forçosamente genéricos para o estabelecimento desses critérios. concernentes a um macro-projeto para Monsaraz. apresentam-sc os cinco pontos a seguir.

\subsection{Paisagem Natural no Grande Entorno}

É indispensável proteger a paisagem do grande entorno do montc $\mathrm{cm}$ cuja crista se acha implantada a vila. Em principio, é desejável que as propriedades nurais de hoje em dia, nesse grande entorno, conservem sua função agrícola. Em outras palavras: deve ser evitado o alargamento de urbanizações já cxistentes ao redor do monte. Tal providência permitirá continuidade no fluir da paisagem de área representativa da planicic alentejana.

Os critérios referidos deierão preier mudanças na paisagem que advirão quando estiver concluída a obra do Alqueva. A grande represa do rio Guadiana, aliás. virá a constituir-se em outro importante atrativo a dinamizar atividades turísticas e de lazer, que deverão ser assunto de cuidadoso plancjamento para se cvitarem as conseqüencias do perigoso turismo de massa. Conforme se sabe. o turismo se impõe como um fenômeno mundial com dimensões crescentes, em que o diferencial da natureza co da cultura se colocam entre os mais procurados. Não havendo como fugir a csse fenômeno mundial. ć altamente recomendável elaborar-sc um plancjamento especifico para se implantarem adequados padrões de atividades. minimizando conflitos: afinal. cstudos de sociologia do turismo mostram que nem sempre o turismo é um "inimigo" ou um "cabcça oca" talvez de bermudas e camisas espalhafatosas. Monsaraz pode captar lurismes de queliclacke, a traindo visitantes nào interessados $\mathrm{cm}$ vulgaridades.

A necessária proteção/conservação não impedc. entretanto. a melhoria c. pontualmentc, a reconstrução ou adaptação de residências - respeitados estilos pré-existentes - em localidades próximas, como Arrabaldc. Ferragudo, Telheiro, talve\% também lugares mais distantes.

\footnotetext{
7. Estudiosos recomendam a ol,rigatoriedade de se privilegiar a qualidade de vida das populią̧ió fixas de nicleos receptores de turismo (Eugene. 1980: Krippendorf, 1989).

8. Ver a respeito Boo (1990), Krippendorf (1989) e L'nesco (1980).
}

\subsection{Pequeno Entorno}

A encosta e o sopé do montc onde se acha a vila devem reccber tratamento especial, de preservação total. Não será demais planear o replantio de espécies nativas, em harmonia com cultivos de interesse econômico.

\subsection{Intra-Muros}

Evidentemente, a arquitetura c o urbanismo da vila também devem receber proteção total, com código legislativo específico que, ademais de atender ao já estabelecido por dispositivos legais em vigor quanto a bens culturais nacionais, pormenorize a respeito da própria Monsaraz. Há diversas construções na vida que aguardam restauro e providências pertinentes para conservação ativa.

\subsection{Cultura Popular}

Segundo investigações que se têm desenvolvido em Monsaraz, há muitos traços da cultura tradicional-popular que podem somar-se aos outros atrativos, no plano do turismo cultural: culinária regional (já consideravelmente aproveitada nos restaurantes existentes), artesanatos, comemorações tradicionais, cantos c outros. Trata-se de um veio a ser explorado.

\subsection{Ecomuseu}

Monsaraz oferece pré-condições para a instalação de um magnífico Ecomuseu, com características únicas. A realização deste item obriga, naturalmente, muitos estudos, muitas providências preliminares - incluindose a preparação de elemento humano, devendo-se dar preferência a habitantes locais e de lugares próximos - também muitas obras de apoio, muitos contatos de especialistas e de gestores públicos; todos assumindo um real interesse e efetiva vontade política na busca das mais adequadas solu६ð̃es para preservação ativa de uma jóia rara no campo de bens culturais. 


\section{CONSIDERAÇÕES FINAIS}

Os conteúdos dos critérios aqui colocados são temas para debates e cstudos. O GTL - Grupo Técnico Local - da Câmara Municipal de Reguengos de Monsaraz, desenvolve plano especifico sobre Monsaray e por certo elabora propostas adequadas. Entretanto, a rapidez com que ocorrem as mudanças na sociedade industrial ocidental, nestes últimos anos do século XX, paralelamente à situação de desgaste de bens culturais dessà vila alentejana e de seu termo. mostram a necessidade de se agilizarem? providências em tcmpo hábil.

Ademais, também para capitalizar benefícios que poderão advir do incremento de turismo de qualidade. em favor da população local. Embora não haja dados sistematizados, percebe-se que turistas destinados a Lisboa c Évora sequer têm informação da existência do núclco medieval de Monsaraz; e os que chegam a visitá-la o fazem de passagem, apenas unı passeio (portanto, sem conhecer mais de perto o que o lugar tem a oferecer e sem deixar benefícios, como se preceitua modernamente). Perde-se, cntão, a oportunidade de ampliar o movimento de visitantes, por falta de um plano integrado de promoção, cm cuja base deveria estar a preocupaçào com a minimização de impactos negativos e a preservação do conjunto representativo.

Enfim. nos tempos presentes, as lutas de Monsaraz diferem substancialmente daquelas de séculos passados: são lutas pela sua revitalização, como patrimônio cxcepcional, cvitando-se concomitantemente que scja atacada pela massificação, inimiga da identidade cultural.

\section{REFERÊNCIAS BIBLIOGRÁFICAS}

BO(), Elizabeth. 1990. Ecotourism. The potentials and piffalls. Washington: Worid Wildlife Fund, $2 \mathrm{v}$.

EUGENE, Pierre. 1989. Le tourisme. Destructeur ou protecteur de l'environement? Espaces. Paris. n. 48 , out.

KRIPPEND(JRF, Jost. 1989. Sociologia do turismo. Rio de Janeiro: Civilização Brasileira. PELLEGRINI FILHO, Américo. 1993. Ecologia, cultura e turismo. Campinas: Papinus.

UNESCO. 1972. Recomendações da $19^{a}$ Reunião. Unesco: Paris.

UNESCO. 1980. Protection et animation culturalle des monuments, sits et villes historiques in Europe. Bonn: Unesco. 